\title{
JUVENTUDES EM TRÂNSITO: NOTAS ETNOGRÁFICAS SOBRE A RELAÇÃO DOS ESTUDANTES DO ENSINO MÉDIO COM O CONHECIMENTO ESCOLAR
}

\author{
YOUTH IN TRANSIT: ETHNOGRAPHIC NOTES ON THE RELATIONSHIP \\ OF HIGH SCHOOL STUDENTS WITH SCHOOL KNOWLEDGE
}

BORGES, Luiz Paulo Cruz ${ }^{1}$

\begin{abstract}
RESUMO
A relação dos jovens estudantes do Ensino Médio com o conhecimento escolar é objeto de estudo do presente artigo. Pauta-se na abordagem teórico-metodológica etnográfica, situada na fronteira entre a antropologia e a educação. Assim, foram utilizados o caderno de campo, notas etnográficas, descrição densa, entrevistas, fotografias, observação participante e produções textuais como formas de apreender um recorte da realidade social. Articulam-se as categorias conhecimento escolar e juventudes privilegiando uma abordagem pós-crítica e pós-colonial para pensar a escola e seus sujeitos. Questiona-se como jovens estudantes do Ensino Médio de uma escola pública da rede estadual do Rio de Janeiro se relacionam com o conhecimento socializado pela escola? Opera-se numa lógica de que há uma polifonia nas vozes discentes que podem ser escutadas como forma de uma produção curricular pensando os dissensos como caminhos possíveis a partir da ideia de juventudes em trânsito abordando a relação dos jovens com seus processos educacionais e suas imagens. À guisa de conclusão, defende-se a ideia de que o conhecimento escolar, entendido como atos de significação, é uma dimensão criadora dos modos de subjetivação e diferença, capaz de permitir a emergência dos trânsitos juvenis presentes na escola de hoje.
\end{abstract}

PaLAVRA-ChaVe: Conhecimento escolar; Escola contemporânea; Etnografia; Juventude

\begin{abstract}
The relation of the young students of the High School with the school knowledge is object of study of the present article. It is based on the ethnographic theoretical-methodological approach, located on the border between anthropology and education. Thus, field notes, ethnographic notes, dense descriptions, interviews, photographs, participant observation and textual productions were used as ways of apprehending a clipping of social reality. The categories school knowledge and youth are articulated, favoring a post-critical and postcolonial approach to thinking about the school and its subjects. Is it questioned how young high school students from a public school of the state network in Rio de Janeiro relate to the
\end{abstract}

\footnotetext{
${ }^{1}$ Professor do Instituto de Aplicação Fernandes Rodrigues da Silveira da Universidade do Estado do Rio de Janeiro (CAp-UERJ) e da Rede Estadual de Educação do Estado do Rio de Janeiro (SEEDUC/RJ). e-mail: borgesluispaulo@yahoo.com.br
} 
DOI: $10.12957 /$ e-mosaicos.2018.34444

knowledge socialized by the school? It is based on a logic that there is a polyphony in the voices that can be heard as a form of a curricular production thinking dissensions as possible paths from the idea of youths in transit approaching the relationship of young people with their educational processes and their images. In conclusion, the idea is defended that school knowledge, understood as acts of meaning, is a creative dimension of the modes of subjectivation and difference, capable of allowing the emergence of juvenile transits present in today's school.

KeYWORDS: School knowledge; Contemporary school; Ethnography; Youth

\section{INTRODUÇÃo}

Vamos viver nossos sonhos temos tão pouco tempo Então vamos viver e um dia a gente se encontra. (Charlie Brown) ${ }^{2}$

A pesquisa em tela foi desenvolvida junto a alunos e alunas do Ensino Médio de uma escola pública no Estado do Rio de Janeiro, que carregam consigo o qualificador de jovens, ou seja, são os sujeitos da pesquisa que também fazem parte da juventude do país. Jovens, meninos e meninas, afrodescendentes em sua grande maioria; oriundos das classes populares, sendo moradores da Baixada Fluminense, região com sérias questões sociais e econômicas, como por exemplo, falta de estrutura cultural como teatros e falta de saneamento básico, como água e esgoto. Região também marcada por traços da violência e presença de drogas ilícitas.

Boa parte dos jovens estudantes se declararam cristãos do segmento protestante, sobretudo, os neopentecostais ${ }^{3}$. Jovens que vivem uma juventude pautada na incerteza do mundo atual, um tipo de incerteza que se reflete em diversos fluxos culturais pautados na diferença (APPADURAI, 2009). Entende-se aqui que tal juventude está em trânsito, ou seja, integra um grupo social que desempenha um papel em via de mão dupla: i) jovens que são enquadrados como estudantes e por isso mesmo carregam um entendimento pautado no padrão, no uniforme e na expectativa de algo; ii) uma juventude que não cabe em si, mas que, extrapolando suas próprias demarcações se mostra presente no dia a dia da vida escolar com tensões, tráfegos e movimentos, sendo jovens estudantes, ou mesmo, estudantes jovens.

\footnotetext{
${ }^{2}$ Trecho de música escrita na parede do pátio da Escola Alvorada.

3 O neopentecostalismo pode ser considerado um movimento dissidente dos evangélicos que congregam denominações oriundas do pentecostalismo clássico ou mesmo das igrejas cristãs tradicionais, tais como as batistas, as metodistas, etc. Surgiram em meados dos anos 1970, algumas décadas após o movimento pentecostal do início do século XX.
} 


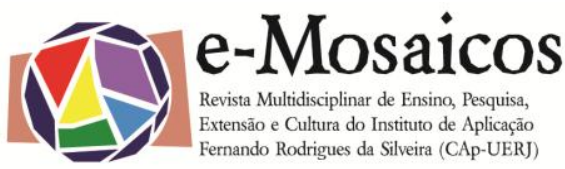

DOI: $10.12957 /$ e-mosaicos.2018.34444

O presente texto abordará a ideia de juventude como quimera escolar pensando as polifonias possíveis presentes dentro e fora da escola. As vozes dos participantes da pesquisa são evocadas, mas não em um sentido de ilustração, ou seja, de mera corroboração para algo já existente. Antes de tudo, parte-se de tais vozes para se construir uma teorização com e para os jovens que estão presentes na escola (MATTOS; ALVES, 2015), uma teorização de como os jovens estudantes se relacionam com o conhecimento escolar. Contudo, indica-se que não há uma fixação do que venha a ser juventude, mas, sobretudo, há uma análise que parte do recorte de um tipo de juventude presente na escola pública, em especial na escola investigada.

São assim indicadas pistas etnográficas de uma categoria que emerge a partir das suas relações com o mundo, com as tecnologias, a linguagem e a cultura. Como subcategorias que consubstanciam a ideia de juventude, estão relacionadas "zoação, muleque, viado, idiota, celular, selfie, sexualidade, igreja, facebook, virtual, bagunça, WhatsApp, matar aula".

Juventude entendida em uma categoria de análise social pulsante, mas que enfrenta sérios embates porque ainda se pretende ser. Jovens que, vivendo no mundo em fluxos distintos, partilham sentidos que convergem e divergem concomitantemente (DAYRELL, 2003; 2007). Dessa forma, parte-se das teorizações sobre os processos educacionais e a escola para se compreender quais são as relações estabelecidas entre a juventude e o conhecimento escolar.

Com o uso da etnografia pretendem-se responder tais questões a partir do plano cultural por sua forma de investigação: observação, descrição densa, entrevistas, notas etnográficas, colaboração, dentre outros. A empiria, a análise indutiva de conteúdo das vozes dos sujeitos na pesquisa e a dimensão imaginativa, já definida como a disputa de sentidos no âmbito da cultura, foram componentes do processo de análise dos dados da investigação.

Podemos pensar que o etnógrafo "se move num campo de gêneros disciplinares difusos, ou imprecisos" (CARVALHO, 2001, p. 109). A etnografia como abordagem de investigação científica traz contribuições para o campo das pesquisas que se interessam pelo estudo das desigualdades e exclusões sociais, de acordo com Mattos (2002), por preocupar-se com uma análise holística da cultura, ou seja, a cultura não é vista como um mero reflexo de forças estruturais da sociedade, mas como um sistema de significados e significantes mediadores entre as estruturas sociais e a ação humana. $E$ também por compreender os sujeitos sociais com uma participação ativa e dinâmica no processo modificador das próprias estruturas sociais.

É preciso compreender que o campo educacional tentando assumir "[...] pontos de vista da Antropologia tenta, antes de tudo, delimitar fronteiras que marcam ambas as áreas e que não podem simplesmente ser dissolvidas, mas repensadas no sentido da articulação que mantém suas identidades e diferenças" 
e-Mosaicos - Revista Multidisciplinar de Ensino, Pesquisa, Extensão e Cultura do Instituto de Aplicação Fernando Rodrigues da Silveira (CAp-UERJ)

V. 7 - N. 15 - AGOSTO 2018 - ISSN: 2316-9303

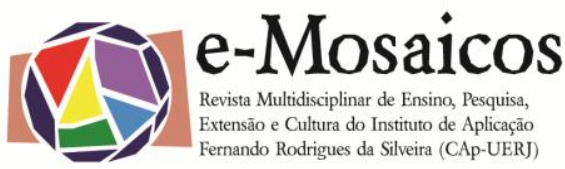

DOI: 10.12957/e-mosaicos.2018.34444

(PEREIRA-TOSTA, 2011, p. 428). Dessa maneira, a escola torna-se lócus profícuo de análise e produção de sentidos sobre os mundos que lá habitam, gerando idiossincrasias necessárias no processo de produção de conhecimento.

Os estudos de Novaes (1995) indicam que o olhar é uma instância ligada à Modernidade, uma simples ação que ganha forma e importância dentro desse contexto histórico-social, o século da razão e das luzes. A visibilidade não foi algo muito apreciada como fonte de conhecimento legitimada na época de Galileu. Olhar para as estrelas ou mesmo pelo telescópio era algo impensado, pelos teólogos da Igreja Romana, dentro da conjuntura do próprio Galileu. Assim sendo, Novaes (1995), organizador do livro $O$ olhar, nos propõe as seguintes questões: o que é ver? O que é o visível?

Carvalho (2001) toca no assunto do olhar a partir da teoria do filósofo Derrida informando que há um descentramento da ação do olhar no mundo ocidental. Tal descentramento ocorre quando a cultura europeia deixa de ser eixo central ou mesmo foi colocada em xeque. Há então uma separação do visível: o do etnógrafo (civilizado) e o do nativo (primitivo), ou seja, perspectivas de mundos distintas. Assim, temos três momentos postos à antropologia na perspectiva do descentramento, ou em tempos de pós-colonialismo.

Como olha o "primitivo"? Tal questão não foi posta em xeque no momento fundante da etnografia. O olhar do primitivo era entendido como um "olhar 'natural', imediato, irreflexivo, direto" (CARVALHO, 2001, p. 110). Assim, o olhar do nativo "constrói sua alteridade segundo o modo em que retruca, de um lugar subalterno, o olhar do colonizador sobre si" (CARVALHO, 2001, p. 111).

O segundo descentramento versa sobre como os etnógrafos dos países subalternos e/ou periféricos aprenderam com os europeus a teoria do olhar partindo de uma perspectiva universalista e europeia. Urge pensar que é preciso "descolonizar as paisagens mentais" (CARVALHO, 2001, p. 111) de forma a delinear uma revisão canônica e teórica da antropologia. Os estudos de Lévi-Strauss inauguraram a possibilidade de que os "primitivos/nativos" (africanos e árabes) olhassem para o etnógrafo (europeu) e, portanto, constituíssem um olhar que possibilitou uma crise e a emergência de uma metamorfose do olhar etnográfico.

O terceiro momento da mudança do olhar versa sobre uma introdução da subjetividade no debate epistemológico da reflexividade da ação etnográfica. Questiona-se a autoridade etnográfica exercida, sobretudo, pela antropologia estadunidense. A crise gestada nos faz pensar que o sujeito moderno, em sua condição de pós-modernidade, desestabiliza o lugar de segurança e de verdade. "(...) e é justamente na construção de suas fronteiras que podemos captar as recusas do sujeito em implicar-se na realidade que interpreta" (CARVALHO, 2001, p. 117).

É tendo em vista esse contexto, o do olhar, que durante toda a presente pesquisa se fez uso do termo observação participante. As implicações dessa 


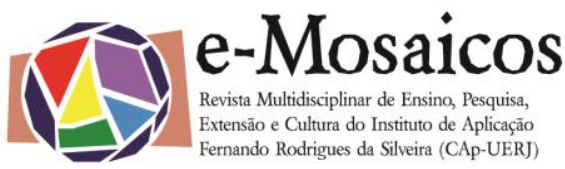

DOI: $10.12957 /$ e-mosaicos.2018.34444

observação no processo de construção do conhecimento são percebidas como um importante instrumento para compreender o saber didático construído no dia a dia da escola, por um determinado período de tempo. Foi assim que o olhar dos alunos e alunas da escola foi se entrecruzando com o olhar do pesquisador. Foram olhares que, se chocando, foram produzindo percepções de mundo. Segundo Lüdke e André (1986), o pesquisador ainda é o principal responsável pela feitura e pela organização das informações investigadas no âmbito da pesquisa e, por isso, guia o olhar na percepção do que deseja investigar. A partir do olhar dos estudantes que participaram nessa pesquisa, há uma complexidade posta às formas de compreensão através do eu e do Outro.

A pesquisa de campo ocorreu com as observações em sala de aula que foram desenvolvidas semanalmente durante sete meses em uma escola pública de Ensino Médio na rede estadual de Educação do Rio de Janeiro em Nova Iguaçu.

Participaram do estudo estudantes da $2^{\mathrm{a}}$ série e $3^{\mathrm{a}}$ série do Ensino Médio. As aulas observadas foram aulas de Química em um regime de colaboração. Ou seja, dentre o universo de docentes na escola, o professor de Química se dispôs a participar da pesquisa como colaborador. Dessa forma, as aulas, o pátio e a sala de professores foram espaços de observação de forma semanal.

As observações geraram notas de campo, que geraram os relatórios de campo, e, enfim, sistematizaram-se os dados da pesquisa. Além da observação participante também foram entrevistados alguns estudantes, aos quais solicitamos que realizassem uma produção de texto perguntando sobre suas aprendizagens e também sobre suas expectativas a partir do inventário de saber de Charlot (2005), de forma que tivemos, como dados, a observação participante com a descrição densa, entrevistas etnográficas e a produção textual, além de documentos produzidos pela Secretaria Estadual de Educação.

Após o campo, tivemos uma etapa de sistematização e análise de dados, foi preciso retornar às entrevistas realizadas e às descrições do caderno de campo para compor as análises do trabalho e levantar as categorias temáticas. Nesse processo também se elegeram outras informações para compor o panorama dos dados: informes sobre a instituição em redes sociais, análise de reportagens em mídias, notas em associações, falas de estudantes em vídeos. Indica-se que a escola produz e também é produtora de uma conjuntura compreendendo aqui uma abordagem dialógica da pesquisa com idas e vindas. Após a organização em blocos de textos, os mesmos foram lidos, relidos e sistematizados em categorias em consonância com o Atlas.ti. Contudo, o olhar do pesquisador no processo artesanal de feitura da pesquisa ainda foi a principal forma de análise dos dados (MILLS, 2009).

A última etapa do processo de produção do relato etnográfico é escrever o texto final de um processo de formação para a pesquisa reflete um desafio proposto em "estar lá" e escrever aqui, entendendo o antropólogo como autor (GEERTZ, 2002). A escrita final pressupõe idiossincrasias que aparecem ao longo do texto. 


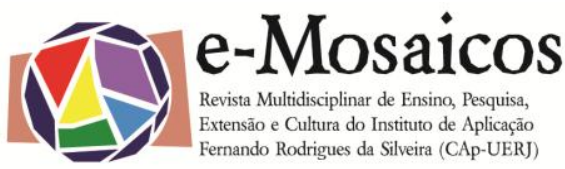

DOI: $10.12957 /$ e-mosaicos.2018.34444

Pressupõe analisar e compreender a partir da ideia de reimaginação posta no plano cultural da significação de sentidos. Escrever o texto etnográfico é criar a emergência de sentidos possíveis, mas também impossíveis para quem não viveu o campo tal qual o etnógrafo. Importante destacar que há rasuras, lacunas, contradições, sendo a etnografia um saber de fronteira, ela nos coloca em perigo, pois não permite uma fixação. Mas, de forma emblemática, da fronteira se pode ver um horizonte mais largo, mais possível.

\section{A JuVEnTUde como Quimera EscolaR: POLIFONIAS POSSÍveIS}

A Quimera é um ser mitológico geralmente representado como um ser de corpo híbrido entre diversos animais: leão, cabra, serpente e/ou dragão. A juventude na escola pode ser considerada uma quimera, uma mistura de crianças/adolescentes com credos diversos, descobrindo e vivendo a sexualidade, reafirmando ideias e posições no mundo, desejando algo para além do vivido entre muros escolares. Já na escola, tal qual a metáfora da quimera, a juventude pode ser a diferença que pulsa e incomoda partilhando suas conexões velozes num mundo global (APPADURAI, 2009).

Dessa maneira, parte-se de uma leitura que ocorra numa perspectiva de se compreenderem os diversos fluxos culturais e também como forma de abarcar as imaginações coletivas e as coletividades imaginadas na era da globalização de raiz (APPADURAI, 2009). Globalização esta entendida como processos mais fluidos e celulares que buscam abrir brechas possíveis para a vida social.

Uma juventude que vive dilemas impostos pela violência, desigualdade social, educação, geografia urbana e social, cultura e lazer etc. Destaca-se a ideia de que a trajetória de participação dos jovens no cenário político também mudou nos últimos anos, como também as relações familiares.

Enfatiza-se o lugar do Ensino Superior para esse grupo, além da difícil procura por trabalho. À medida que tais demandas surgem no horizonte também descortinase o olhar para processos de pertencimento religioso, sexual e cultural de grupos de jovens cristãos, LGBTs, Hip-hop etc. Uma militância, como veremos a seguir com os estudantes da escola pesquisada, fruto de uma participação política que é posta em xeque por indicar formas outras de mobilização. Evidencia-se, por outro lado, que há uma parcela de jovens que vêm morrendo: a juventude negra e pobre , a maior vítima das desigualdades estruturais no país, de forma geral, e, na escola, de forma particular (GONÇALVES PEREIRA, 2012).

Dessa forma, ao longo da pesquisa de campo, no ano corrente de 2015 , foi possível perceber as nuances presentes no âmbito da escola pública investigada. Dimensões presentes que ganharam novos relevos pós-pesquisa no contexto da greve e das ocupações no Estado do Rio de Janeiro no ano de 2016. Embora a presente pesquisa não tenha observado e se debruçado sobre escolas ocupadas, não 


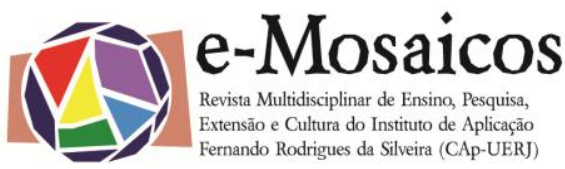

DOI: 10.12957/e-mosaicos.2018.34444

é possível negligenciar que tais ações, ocupações versus desocupações, colocaram em xeque os sentidos da escola e do lugar do conhecimento escolar. Talvez porque, colocando o aluno em centralidade, questionaram-se quais os sentidos de escola entendendo-se os estudantes como protagonistas e suas vozes como audíveis no processo de tomada de decisão acerca das ações no cotidiano escolar.

Chama-se atenção, dessa forma, quanto à ida do pesquisador para a região metropolitana de educação, METRO I, em Nova Iguaçu-RJ, encontrando estudantes da escola investigada, agora já na $3^{\text {a }}$ série do Ensino Médio, em protesto na rua. Uma ida burocrática que possibilitou uma reflexão sobre os novos sentidos da escola pós-pesquisa de campo. Um "momento de acaso", mas que, em etnografia, se revela como dado. $O$ acaso etnográfico foi a possibilidade do encontro e da necessária reflexão do pesquisador para os projetos possíveis, dentro e fora da escola. Uma etnografia que, sensível à realidade de seus sujeitos, produz uma dimensão socialmente engajada, ou seja, em comprometimento com o outro, que, neste caso, são alunos e alunas da escola pública fluminense.

Os estudantes na rua, meninos e meninas, estavam uniformizados e carregavam cartazes com dizeres sobre a situação da escola e da educação, protestavam. Os dizeres revelavam desejos, ou mesmo ideais, não se sabe ao certo. Contudo, revelavam as vozes da condição juvenil presente no mundo que desejam outra escola, outras representações e, quem sabe? Outra sociedade. A juventude é um trânsito que se dá no confronto, no vaivém do possível, às vezes, impossível. Juventude é movimento.

Vozes ampliadas pelo espaço da rua diziam: "Chame minha escola de olímpica e invista nela", comparando o desejo de que a escola pública ganhasse mais investimentos que as Olímpiadas na Cidade do Rio de Janeiro no ano de 2016, ano dos jogos na cidade. "Ia iscreveraugu legal, mais fautôedukssão" (Íamos escrever algo legal, mas faltou educação), usavam uma linguagem não-padrão para expressar como a própria linguagem pode significar educação de qualidade, ou seja, que precisam dominar uma forma específica, norma padrão da língua, para garantir sucesso. "Quero estudar e o governo não deixa", se referindo à falta de investimentos do governo estadual do Partido do Movimento Democrático do Brasil (PMDB), na atual gestão, do governador Pezão.

Por fim, "Deve ser pra ladrão ver uma geração crítica ao invés de alienada", significando políticos como ladrões que não querem ver "uma geração crítica" e, sim, "uma geração alienada", geração entendida como de jovens. Assim, entendendo crítico e alienado como dimensões em disputa da linguagem e de uma compreensão marxista da realidade que se contrapõe em uma luta de classes.

$O$ encontro com os estudantes indica possibilidade para pesarmos com Appadurai (2009) em uma analogia necessária no mundo hoje: o mundo celular e o mundo vertebrado. Tomando de empréstimo tais asserções, pense-se aqui a escola 
DOI: $10.12957 /$ e-mosaicos.2018.34444

como sistema vertebrado e os estudantes, a juventude, como sistema celular. Escola e juventude que, em contradição, disputam sentidos, linguagens etc.

O mundo vertebrado, aqui entendido, em analogia, como a escola, tem uma estrutura que valoriza e pressupõe uma ordem, normatizações, protocolos e controle regulados e signatários (APPADURAI, 2009). Já a dimensão celular, aqui caracterizada pela e na juventude escolar, pressupõe independência negociada, horizontalidade nas relações, novas formas de solidariedade e novas formas de estratégias de poder e contestação.

Parte-se dessa analogia, celular e vertebrada, para pensar o que os/as jovens aprendem na escola e como suas vozes, também dissonantes, revelam dimensões celulares presentes no dia a dia, ou seja, autonomia, compreensão não sistematizada, horizontalidade, solidariedade etc.

As vozes desses sujeitos na rua indicam uma forma de consciência e revelam dissonâncias, tal qual o que se aprende na escola: conhecimento entendido como conteúdo, ou dimensões de algo aplicável? Por que não conteúdo e aplicação? É preciso pensar que não se pode, mais, dicotomizar tais dimensões: conteúdo e vida cotidiana. Aqui se deseja entender que os imbricamentos nos processos educacionais da busca pela vida geram conteúdo. E que o conteúdo socializado pela escola gera condição de vida.

Se a dimensão da vida e do conteúdo brigam para se hegemonizarem no dia a dia da escola, há que se pensar nas disputas de sentidos sobre este lugar. Existe uma tensão presente nos processos educacionais que estão relacionados a um não consenso. Assim, seguem falas de estudantes presentes na página do Facebook da escola falando sobre a própria instituição. O Facebook é uma rede social que foi criada em 2004 e está presente em diversas partes do mundo global. Foi no intuito da pesquisa que foram mapeadas frases presentes na página da escola, postadas pelos estudantes.

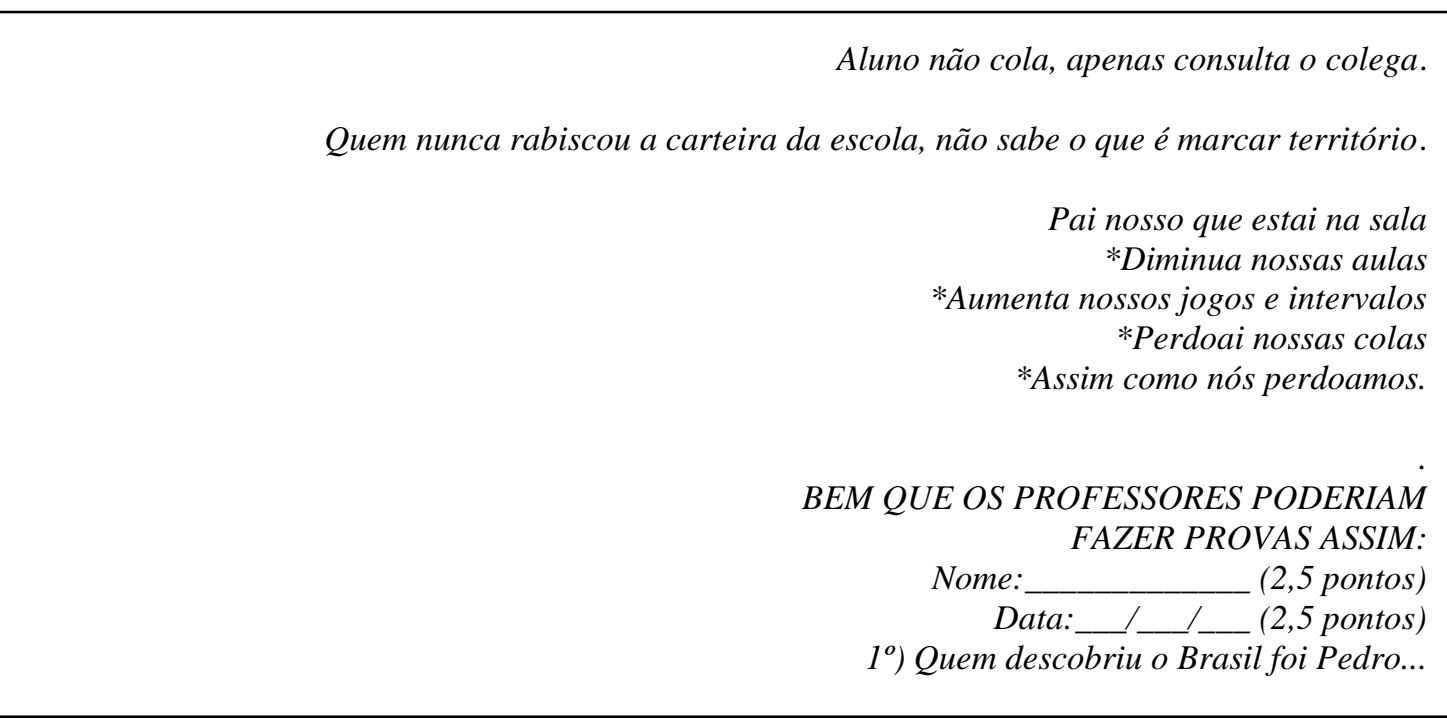


De acordo com as falas nas redes socais, e o protesto descrito acima, podemos depreender que não há um único movimento. Antes de tudo, há movimentos, no plural, que indicam transitividades da juventude como categoria no Ensino Médio da escola pesquisada. São instâncias de negociação que perpassam pelas relações, não somente existentes na própria escola, mas que são estabelecidas fora dela como no WhatsApp, no Facebook, no baile funk, na igreja etc.

As diversas narrativas revelam a riqueza inerente ao simples fato de serem jovens e viverem os movimentos que a juventude acarreta: linguagens, modos de se vestir, questões de gênero e sexualidade, disputa de identidade de raça/cor, posições políticas e religiosas, relação com a tecnologia... enfim, evidenciam a diferença como lugar de se dizer no mundo. Revelam uma escola que é contraditória, podendo ser encarada como "chata", mas que de uma forma ou de outra, se faz presente nas trajetórias juvenis.

Luiza, com 17 anos, estudante da $3^{a}$ série do Ensino Médio, e se identificando como aluna negra, revela dimensões dessa trajetória juvenil permeada de nuances como a violência de apanhar do pai, o "gosto pelo estudo" e o desejo de uma perspectiva melhor.

Vim de uma família que desde criança venho aprendendo coisas "ruins". Meu pai chegando bêbado em casa e eu e meus três irmãos apanhando sem motivo (Entrevista de Luiza, 17 anos, $3^{\text {a }}$ série do E.M.).

Se a vida de Luiza é permeada de sentidos de mudança para romper com o seu modelo familiar, temos as falas de Simone e Joana, ambas com 16 anos, estudantes da $3^{a}$ série do Ensino Médio, indicando também que aprendemos muitas coisas fora da escola, ou seja, que o conhecimento de mundo também faz parte da vida.

A vida é um aprendizado, tanto na rua, em casa ou em qualquer lugar a gente aprende alguma coisa (Produção textual da aluna Simone, de 16 anos, $3^{\mathrm{a}}$ série do E.M.).

Bom, em cada lugar se aprende um pouco. Na rua as coisas são boas e ruins, mas nos ensina muitas lições. Em casa é o aprendizado principal, pois onde aprendemos tudo que é necessário para enfrentar uma vida normal (Produção textual da aluna Joana, de 16 anos, $3^{\mathrm{a}}$ série do $\mathrm{E}$. M.). 
e-Mosaicos - Revista Multidisciplinar de Ensino, Pesquisa, Extensão e Cultura do Instituto de Aplicação Fernando Rodrigues da Silveira (CAp-UERJ)

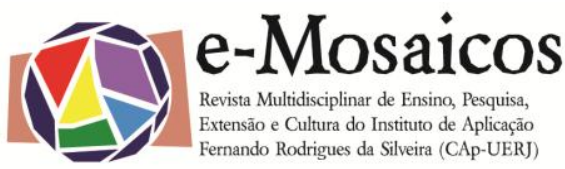

DOI: 10.12957/e-mosaicos.2018.34444

As vozes possíveis, aqui apresentadas, indicam que precisamos apostar na reconstrução da ideia de imagem da escola em sua relação com a vida: "em qualquer lugar a gente aprende alguma coisa". Retoma-se, novamente, a ideia dos processos culturais globais presentes na noção de imaginação como prática social (APPADURAI, 2004). Uma prática social, revelada a partir das falas acima, que indica possibilidades para se pensar: quais seriam as relações possíveis entre jovensconhecimento-escola?

A voz de Frida, aluna da $2^{a}$ série do EM, revela o lugar de uma juventude presente no/com o mundo e na escola. Uma juventude que foi tracejada de diversas formas, sobretudo, por questões relativas à vida pessoal, ao casamento, ao mundo do trabalho. Mas que responde o que é a escola em sua vida.

Entrevistador: para você o que é a escola em sua vida?

Aluna Frida: muita coisa. Porque se a gente não estudar. Eu tentei trabalhar e estudar, mas eu vi que não ia fazer nenhum dos dois, então eu tive que optar por um, ou eu ia trabalhar e ia continuar trabalhando com aquele salarinho ou ia crescer, não tenho estudo ia sempre ser aquilo. Então eu estudando, voltando pra escola eu tenho oportunidade de arrumar um trabalho melhor. Posso perder dois anos sem ganhar dinheiro pra eu comprar minhas coisas, passando uma necessidade, mas dois anos eu vou terminar meu ensino, vou arrumar um trabalho e um trabalho melhor. Positivo é que a gente lá na frente vai ter uma recompensa. Vai arrumar um trabalho bom, vai ter a recompensa. E pra mim de negativo é a falta de tempo, negativo da escola é que as vezes a gente que estudar e não consegue por falta de tempo. Fora isso, escola é pra ensinar e aprender (Entrevista aluna Frida, $2^{\mathrm{a}}$ série do Ensino Médio).

Os jovens são entendidos como quimera escolar e são desejosos de uma escola que querem de outra forma, uma escola reimaginada e possível. Aposta-se aqui numa juventude em trânsito, em processos que se relacionam com o conhecimento escolar a seu modo. Na perspectiva da etnografia, aqui apresentada, reafirma-se a ideia de que as vozes dos estudantes são compreendidas numa gramática da própria produção etnográfica, ou seja, numa relação dialógica entre o pesquisador e os sujeitos pesquisados no plano cultural (APPADURAI, 1988). A etnografia se faz necessária por fazer emergir a voz, o contexto e o texto no plano cultural.

Já na relação conhecimento escolar e juventude, tomando-se as vozes dos sujeitos, pode-se pensar nas palavras de Mattos e Alves (2015, p.11), em que é preciso olhar "os caminhos a trilhar a partir dessa perspectiva e preocupações que 
DOI: 10.12957/e-mosaicos.2018.34444

são inerentes a confrontações e delimitações e partem da própria dialética do campo de pesquisa e da educação". E as autoras continuam reafirmando:

[...] possibilidades a serem criadas a partir da voz dos alunos permite compreender que é possível articular mecanismos de transformação da realidade educacional atual, onde o ensinar não se restrinja a uma mera transferência de conhecimentos, mas que seja lugar de vida, de produção de conhecimento e de vicissitudes que propulsionem novas formas de interpretar, ver e ouvir a realidade a partir do outro. Em particular, invertendo-se as relações hierárquicas de poder e flexibilizando a assimetria existentes entre elas (MATTOS; ALVES, 2015, p. 11).

Os processos educacionais, entendidos como saberes e práticas de avaliação, currículo, didática etc. Precisam ser pensados numa perspectiva cultural e da linguagem, que muitas vezes, entre o crítico e o pós-crítico, são apagados na produção acadêmica, mas que nos ajudam a enxergar o recorte de realidade proposto pela pesquisa etnográfica. Já o olhar etnográfico auxiliou na compreensão do conceito de juventude como trânsito, ou seja, como movimento da realidade social e da vida escolar, assim, relaciona-se as juventudes em trânsito diante dos processos educacionais e a escola. Uma juventude que se move e comove, que encontra na escola vias de tensões e mediações. Uma juventude que pode ser encarada como quimera, um bicho de muitas formas que assusta e que põe em xeque a própria instituição, problematizando-a e causando desconforto.

\section{À GUISA DE CONCLUSÃo}

Ao passo que a pesquisa se desenvolve, também se desenvolvem diversas compreensões sobre o objeto de estudo proposto. Aqui, a relação dos jovensestudantes do Ensino Médio de uma escola pública estadual com o conhecimento escolar. A etnografia torna-se, também, um paradigma que, igualmente, se desenvolve com o objeto de estudo.

Mattos (2017) chama atenção para a ideia de que a etnografia, em tempos de caos, tem ganhado destaque no meio acadêmico por tornar-se uma condição necessária que vem dando sentido à pesquisa educacional na e sobre a escola. A autora continua nos instigando a pensar que "a beleza e o mistério da busca do etnógrafo é encontrar histórias inesperadas, as histórias que desafiam as teorias prontas" (MATTOS, 2017, p. 121).

A reflexividade proposta pela etnografia aqui exercida auxilia no entendimento de que o processo de produção de conhecimento na pesquisa educacional é um compósito da relação reflexividade - vozes discentes - práticas de significação na 
DOI: $10.12957 /$ e-mosaicos.2018.34444

escola. Tais dimensões mobilizam o questionamento sobre que escola e que conhecimento - escolar - hão de existir no futuro.

Bhabha (2011), mais uma vez, sinaliza para a ideia de que, ao olhar para trás, vamos indo para frente. Esse paradoxo proposto é uma forma de, a partir da linguagem, construir uma via possível como chave de resposta. O existir, talvez, seja o que está permeado, ou mesmo impregnado, de sentidos que precisam transcender a ideia de verdade colonial moderna. Aqui, argumenta-se, então, que a escola é o lugar da existência e resistência de diversas formas de crenças e conhecimentos presentes hoje no mundo moderno: docentes resistindo em suas redes e estudantes em resiliência.

\section{REFERÊNCIAS}

APPADURAI, A. O medo do pequeno número: ensaio sobre a geografia da raiva. São Paulo: Ed. Iluminuras: Itaú Cultural, 2009.

APPADURAI, A. Disjuntura e diferença na economia cultural global. In: Dimensões Culturais da Globalização - A modernidade sem peias. Ed. 2004 (Lisboa: Editorial Teorema), p. 43-70, 2004.

APPADURAI, A. Place and voice in Anthropological Theory. Cultural Anthropology. Vol. 3, n. 01, pp. 36-49, 1988.

BHABHA, H. O Bazar Global e o Clube dos Cavaleiros Ingleses. Rio de Janeiro: Editora Rocco, 2011.

CARVALHO, J. J. O olhar etnográfico e a voz subalterna. Revista Horizontes Antropológicos. Porto Alegre, ano 07, n. 15, p. 107-147, 2001.

CHARLOT, B. Relação com o saber, formação dos professores e globalização: questões para a educação hoje. Porto Alegre: Artmed, 2005.

DAYRELL, J. A escola "faz" as juventudes? reflexões em torno da socialização juvenil. Educação e Sociedade. Campinas, vol. 28, n. 100, especial, p. 1105-1128, 2007.

DAYRELL, J. O jovem como sujeito social. Revista Brasileira de Educação. n.24, p. 40-52, 2003.

GEERTZ, C. Estar lá: a antropologia e o cenário da escrita. In: GEERTZ, Clifford. Obras e vidas: 0 antropólogo como autor. Rio de Janeiro, Editora da UFRJ, p.11-40, 2002. 
DOI: 10.12957/e-mosaicos.2018.34444

GONÇALVES PEREIRA, J. Mobilização Nacional Pró-Saúde Saúde da População Negra: impactos e desdobramentos na agenda do ano internacional dos povos afrodescendentes e da juventude. Revista da Associação Brasileira de Pesquisadores(as) Negros(as). ABPN, v. 04, p. 80-96, 2012.

LÜDKE, M.; ANDRÉ, M. E. D. A. Pesquisa em Educação: abordagens qualitativas. São Paulo, EPU, 1986.

MATTOS, C. L. G de. (coord.) Imagens da Exclusão. Projeto de Pesquisa. Rio de Janeiro, Departamento de Educação, UERJ, 2002.

MATTOS, C. L. G. ALVES, W. B. Outros saberes sobre a escola: a voz do aluno na pesquisa em educação. In: Maria do Socorro Lucena Lima; Maria Marina Dias Cavalcante; José Albio Morreira de Sales; Isabel Maria Sabino de Farias. (Org.). Didática e prática de ensino na relação com a escola. 1ed.Fortaleza: EdUECE, 2015, v. 1 , p. $03435-03446$.

MATTOS, C. L. G. Fazendo etnografia em tempos de caos: o movimento a "voz do aluno" como impulsionador de mudanças na escola. In. Universidade e participação: inclusão, ética e interculturalidade. Monica Pereira dos Santos, Ângela Maria Venturini, Jose Guilherme de Oliveira Freitas, Elisa Macas, Regina Maria de Souza Correia Pinto, (organizadores), Curitiba: CRV, p. 109-127, 2017.

MILLS, C. W. Sobre o Artesanato Intelectual e outros ensaios. Rio de Janeiro: Zahar, 2009.

NOVAES, A. De olhos vendados. In: NOVAES, A. (Org.) O Olhar. São Paulo. 5ed. Companhia das Letras, p.09-20, 1995.

PEREIRA-TOSTA, S. Antropologia e educação: culturas e identidades na escola. Magis, Revista Internacional de Investigación en Educación, 3(6), 413-431, 2011. 